\title{
Correction to: Gesture: A Transsubjective Tool to Understand a Work of Architecture
}

Pedro Marques de Abreu, Jorge Tavares Ribeiro, Patrícia Esteves and Zoï Kapoula

Correction to:

Chapter "Gesture: A Transsubjective Tool to Understand a Work of Architecture" in: Z. Kapoula et al. (eds.), Exploring Transdisciplinarity in Art and Sciences, https://doi.org/10.1007/978-3-319-76054-4_10

The original version of this chapter unfortunately contained a mistake. Jorge Tavares Ribeiro was not listed among the authors. This has been corrected.

The updated online version of this chapter can be found at https://doi.org/10.1007/978-3-319-76054-4_10 